\title{
NOTES ON THE BURROWS OF VARANUS bENGALENSIS IN AND AROUND AGRA
}

\author{
Dayal Prasad Gupta and A.K. Sinha ${ }^{1}$ \\ 'Professor and Head, Department of Zoology, Faculty of Science, Dayalbagh Educational Institute, Dayalbagh, Agra, \\ Uttar Pradesh 282005, India \\ E-mail:sei@nde.vsnl.net.in
}

\begin{abstract}
Characteristic patterns of burrows of Monitor Lizards were studied in semi-arid region of Agra. It was observed that the size of burrows in the three study sites was almost similar. The burrows were studied in various microhabitats, viz., elevated land, small mounds, termite nests, wall crevices, drains and gutters and hollow tree trunks. The concentration of burrows was more in Acacia-Saccharum junctions where the Monitors can find prey as well as hide from predators.
\end{abstract}

\section{Keywords}

Burrows, Varanus bengalensis, Monitor Lizard, termitaria, microhabitat, tunnel characteristics, Agra

\section{Introduction}

The Agra region falls in the Gangetic Plains of India. It is a semiarid zone and has various microhabitats, which are utilized by Monitor Lizards, Varanus bengalensis, for making burrows/holes with different characteristic patterns. Burrows serve as shelter places for Monitors from predators and also as resting place during adverse climatic conditions. Monitors occupy a spectrum of burrows, either dug by self or occupying existing burrows of other animals after enlarging them. These lizards have a typical sense of locating their burrows. A general description on the above pattern and characteristics of holes is available in Auffenberg (1983), who describes the burrow utilization by Monitors. These burrows are also referred to as holes or nests.

The present study was conducted between October 1995 and October 1998 at three different sites namely Sikanderpur, Jamuna Pump and Sayeed-ka-tila in the Jamuna catchment area of Dayalbagh, Agra (Figure 1). These sites are located at three different turning points of River Jamuna. The three habitats were characterised by the presence of sand dunes, cultivated land, riverbank, forest and small depressions.

Holes in the ground, in elevated land, in small mounds, in termitaria, wall crevices of the buildings in adjacent human inhabited area, drains and gutters and hollow tree trunks were investigated.

The present study on the burrow pattern and its characteristics in Varanus bengalensis was part of a project on ecology, behaviour and genetics of Indian Varanus by the authors.

\section{Methodology}

In each site, sampling area measuring $1 \mathrm{~km} \times 1.5 \mathrm{~km}$ was selected for study, which was further divided into smaller transects of $100 \mathrm{~m} \times 150 \mathrm{~m}$. In each sampling area 10 smaller transects were randomly selected for sampling.

The width of the hole mouth was measured with a scale whereas, the depth of the hole at which the tunnel terminated was taken by a stick in unitunnel type and then measured with a scale. Since multitunnel burrows usually pose difficulty in measurements, fresh cane sticks were used due to their capacity to bend in an angular tunnel under light pressure.

\section{Results}

The mean length and diameter of the Monitor burrows was $106 \mathrm{~cm}$ and $6.3 \mathrm{~cm}$ respectively. Mean length of each tunnel in multitunnel was also $106 \mathrm{~cm}$. Externally the mouth of the burrow had a convex roof. The cross section of the burrows showed that they open into a straight $1-1.3 \mathrm{~m}$ deep cylindrical tunnel, terminating in to a flat resting chamber almost equal to the size of the occupying Monitor (Figures $2 \& 4$ ).

More frequently, the burrows were found on elevated sand mounds that the Monitors dug themselves. During our study 75 holes were investigated at ground level, i.e. elevated land, small mounds, termitaria, drains and tree trunk (Table 1). Population density of Monitors was estimated based on the presence of Varanus in the burrows (active holes), drains and tree trunk in the three study sites.

Most of the burrows (65.33\%) were live (active). Microhabitat 


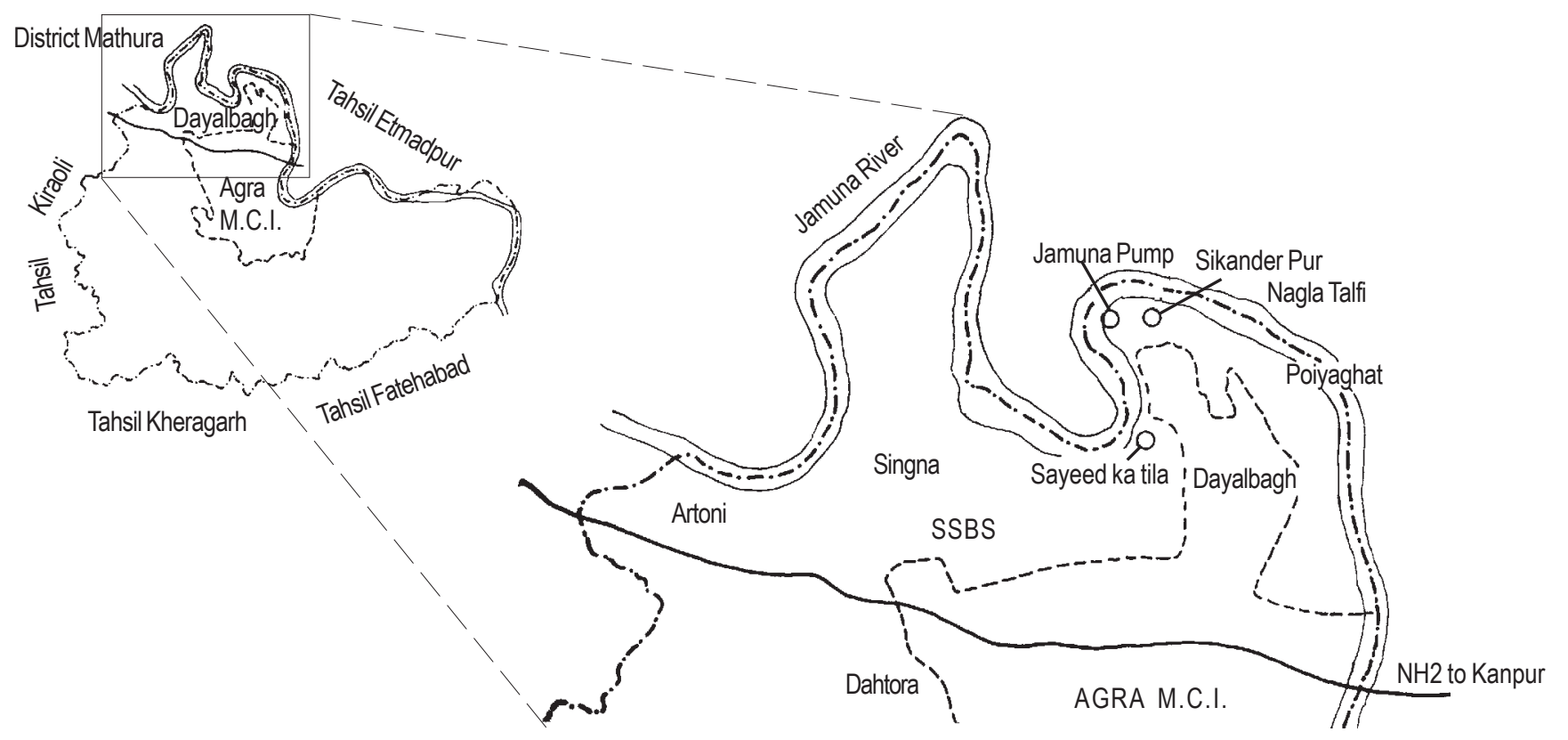

Figure 1. Map showing the study area along with the three sampling sites

utilization studies were made in different habitats of River Jamuna. The burrows were observed in the following microhabitats:

Elevated areas: The study revealed that Monitors preferred angular slopes, where they dig tunnels 1-1.3 m deep down the earth surface culminating into a small resting chamber proportionate to their body size, in which they rest for a short time during active period and for a longer duration during hibernation.

Small mounds: Generally these burrows were observed in open agricultural fields where small mounds are present usually on the boundaries surrounding the field. Such burrows may be preferred due to the availability of abundant food (mice, insects and other food) in agricultural fields.

Termite nests: The nests of termites (termitaria) were mainly noticed on small hillocks and heaps of earth near dead and dry tree base, which serve as food for termites. In our study it was observed that Varanus bengalensis prefers termite as food. In such termitaria, there were natural hollow clefts on top, which led into narrow tunnels. The Monitors enlarge such clefts and tunnels for their shelter,

Wall crevices: Varanus bengalensis were also sighted in various wall crevices in human inhabited areas near the study site. Authors were on various occasions approached by the residents of these areas to capture Varanus bengalensis, as they were scared that it would harm them. Villagers wrongly believe Varanus bengalensis to be highly poisonous.

Drains and gutters: Varanus bengalensis were also noticed in manholes and drains. The necessity to move to such areas may be due to the availability of food in the form of cockroaches, crickets and toads. Generally, they inhabit crevices in the drain and capture their prey easily. This may be a transit phenomenon.

Hollow tree trunk: Few sightings of these lizards were also recorded in hollow tree trunks (Fig. 2). This may be due to the fact that they also feed on eggs of birds, which are likely to be found on the tree. The tree trunk has an opening at the base (ground level) through which a vertical tunnel opens at another point at a height of approximately $4 \mathrm{~m}$ above the ground.

\section{Discussion}

Varanus bengalensis have often been encountered at or near the interface between water and land, usually at AcaciaSaccharum junctions; on the basis of this, the three sites were selected at different riverbank locations. Maximum population density was observed in the Jamuna Pump area. The habitat of this study site is a mixture of all types of land forms available among three sites, i.e. flat land, elevated land on the river banks, sand dunes with sandy loam and forest. The vegetation is in the form of small clusters, predominantly of Acacia among trees and Saccharum among shrubs, such vegetation provides natural cover for Monitors and their prey and also help in 


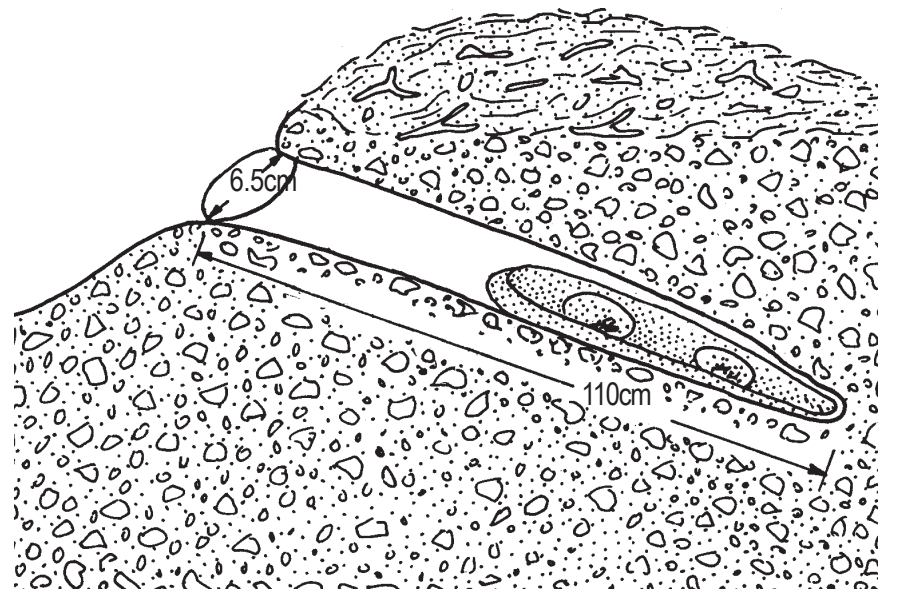

Figure 2. Hole arcitecture in a unitunnel type of burrow

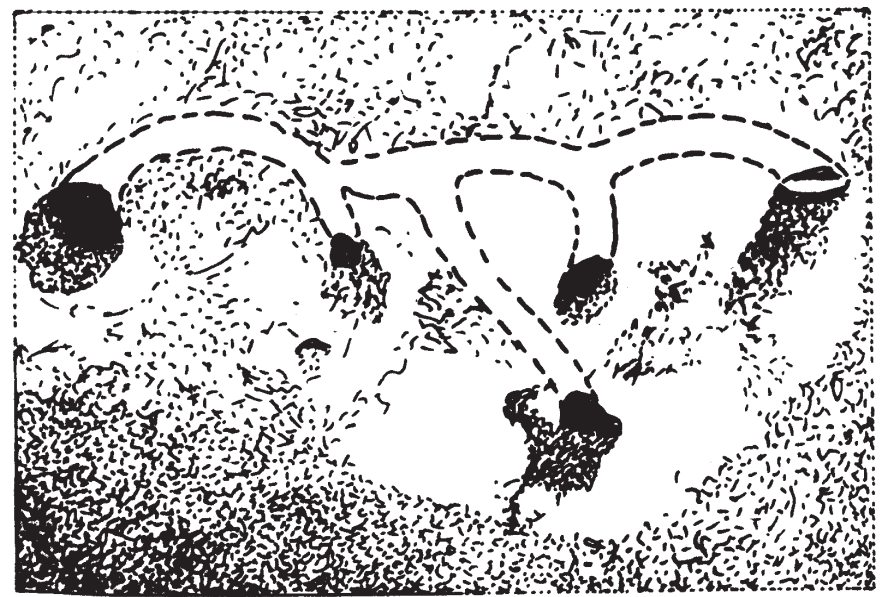

Figure 3. Hole arcitecture in a multitunnel type of burrow in the termite nest thermoregulation during summers. The concentration of Varanus burrows in these areas was high. The building of nests/ holes in soft and loose soil is easier than having it in hard dry soil. Because of elevated land with loose sandy soil on the riverbanks and multiple land types available in this site the number and density of Monitor holes is also high. Although we have not come across any report which substantiates this behaviour in other species of Varanus.

Varanus bengalensis is reported to take shelter in cracks caused in the earth due to earthquakes (D'Abreu, 1932), but in our study we did not encounter such sightings. There are reports of Varanus bengalensis in wall crevices (Daniel, 1983), we sighted two shelter places in wall crevices during the study. Minton (1966) observed these lizards in drain pipes, which were also made during our study. Smith (1930), reported presence of Varanus in hollow tree trunk, similar observations were made during our study only in Jamuna Pump area. The holes appeared to be an abandoned nest of some bird. Though, there is no

Table 1. Population density of Varanus bengalensis at three different sites of the study area

\begin{tabular}{llllll}
\hline Sampling site & $\begin{array}{l}\text { No. of } \\
\text { ground } \\
\text { burrows }\end{array}$ & $\begin{array}{l}\text { No. of } \\
\text { active } \\
\text { ground } \\
\text { burrows }\end{array}$ & $\begin{array}{l}\text { Hollow } \\
\text { Tree }\end{array}$ & Drains & $\begin{array}{l}\text { Est. } \\
\text { popul. } \\
\text { size }\end{array}$ \\
\hline Sikanderpur & $22(10)$ & 15 & 0 & 1 & 16 \\
Jamuna Pump & $35(10)$ & 22 & 3 & 0 & 25 \\
Sayeed-ka-tila & $18(10)$ & 12 & 0 & 2 & 14 \\
\hline
\end{tabular}

${ }^{*}$ Number of transects in parentheses reporting of Varanus from gutters by earlier workers, during the current study in Sayeed-ka-tila we noticed Monitors, twice in the gutters of buildings, where possibilities to find prey in the form of cockroaches is high.

We observed maximum burrows at ground level. Burrows have also been reported at ground level by other workers (Mahendra, 1931; Auffenberg, 1983). The reason may be that such burrows are easily approachable to escape predators. We also made few sightings of Monitors in termite nests. The abandoned termitaria have a crater-like opening at its peak, which was modified by Varanus for its occupation. The most important finding of this study is that the width of the burrows were of uniform size though the size of the Varanus living in it differed. It is general assumption that the body size should determine the width of the burrow's mouth. Our studies defy this general assumption, as the width of the burrow mouth appears to be independent of body size of the lizard.

\section{Acknowledgements}

Authors are thankful to Mr. Anand Swarup, Faculty of Engineering, D.E.I., for making meticulous text figures. We are also thankful to Mr. Hari (animal catcher) for trapping Varanus from burrows and the villagers of the study area for providing necessary information about the lizards from time to time.

\section{References}

Auffenberg, W. (1983). The burrows of Varanus bengalensis: characteristics and use. Records of the Zoological Survey of India 80: 375-385.

D'Abreu, E.A. (1932). Notes on the Monitor Lizard. Journal of the Bombay Natural History Society 36(1): 269-270.

Daniel, J.C. (1983). The Book of Indian Reptiles. Bombay Natural History Society, $400 \mathrm{pp}$. 


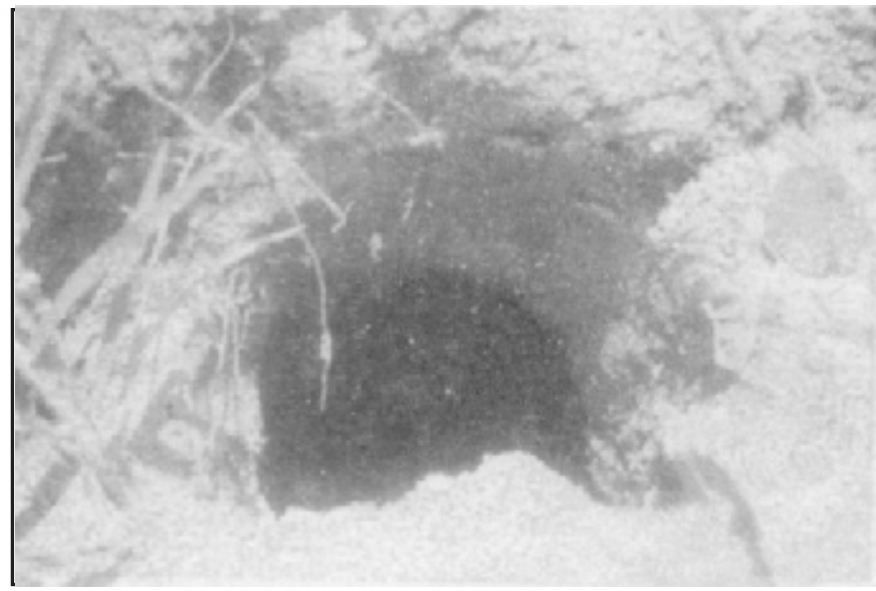

Figure 4. Mouth of the burrow with convex roof

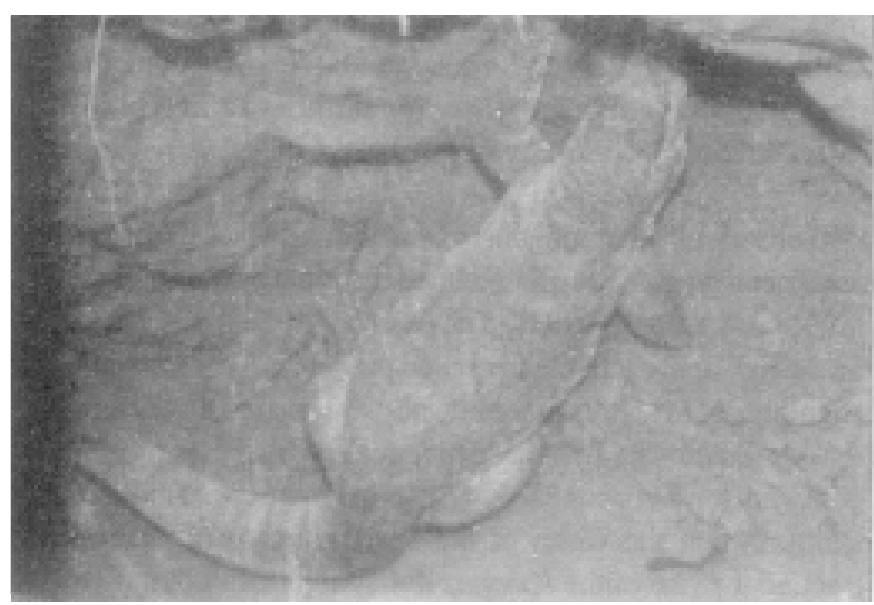

Figure 5. Resting chamber of unitunnel burrow

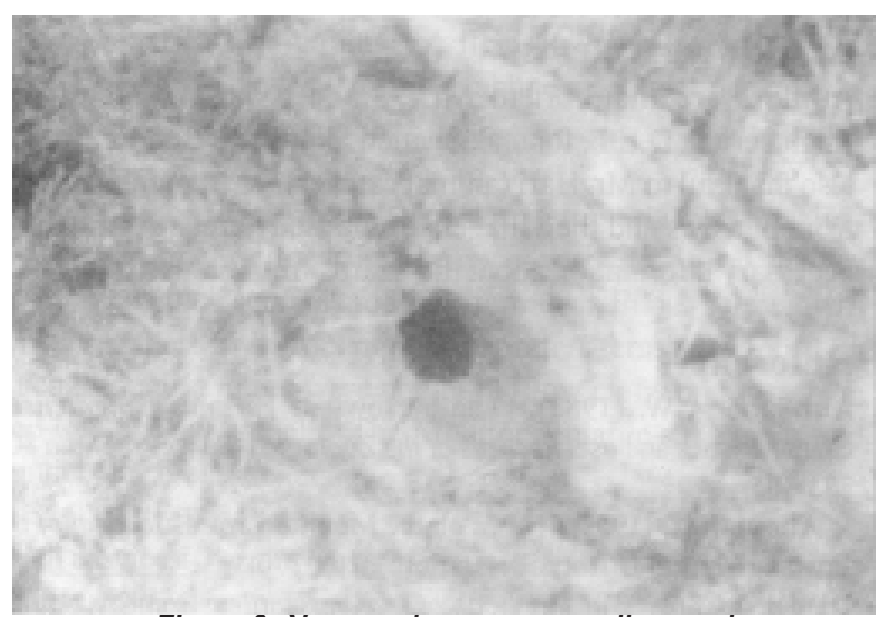

Figure 6. Varanus burrow on small mound

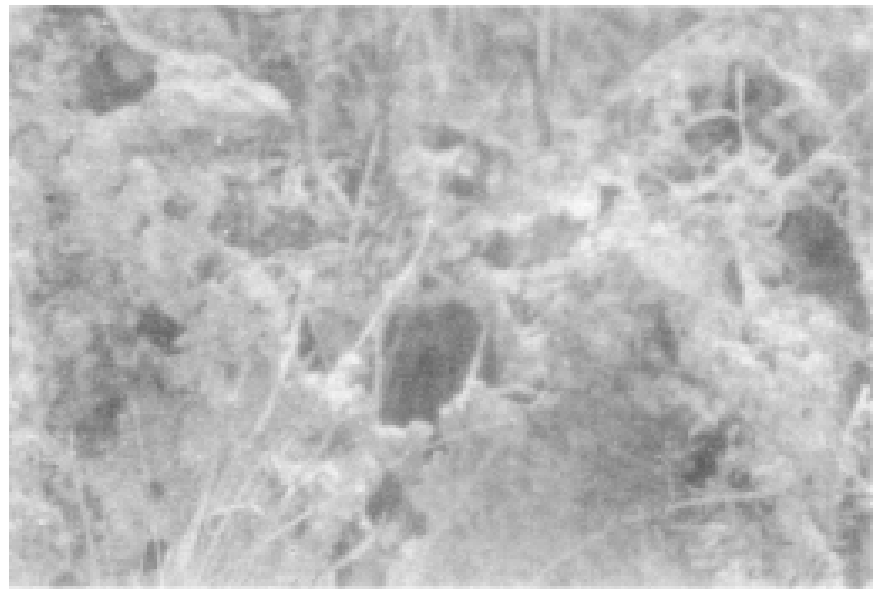

Figure 7. Varanus burrow in the termite nest

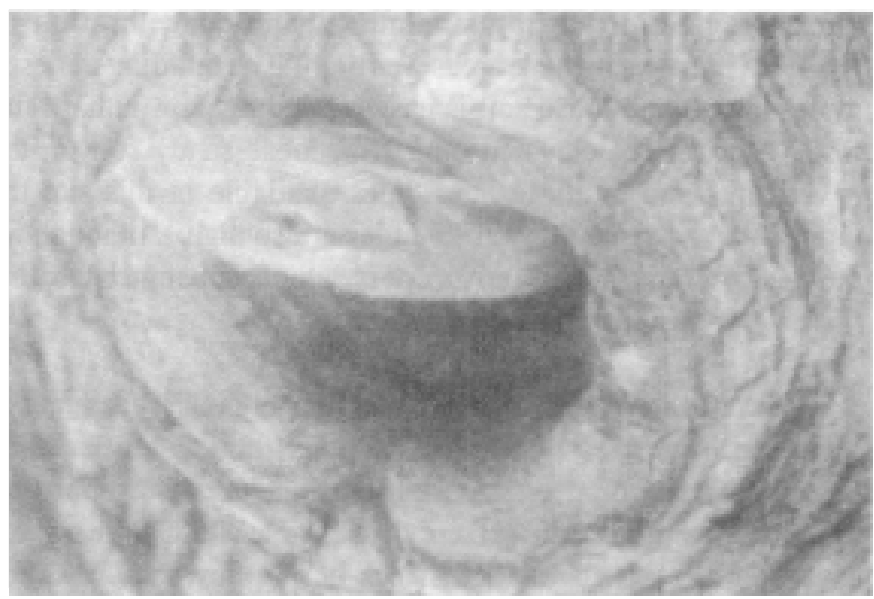

Figure 8. Varanus peeping out of a hollow tree trunk - a type of shelter

Mahendra, B.C. (1931). How the Monitor sits in the burrows. Journal of the Bombay Natural History Society 34: 255-256.

Minton, S.A. (1966). A contribution to the herpetology of western Pakistan. Bulletin of the American Museum and Natural History 134: 27-184.

Smith, M.A. (1930). Reptilia and Amphibia of the Malay Peninsula. Bulletin of the Raffles Museum 3: 1-149. 